\title{
CASE STUDIES OF SUSTAINABLE URBAN MOBILITY PLANS AND MEASURES IMPLEMENTED IN THE FRAMEWORK OF THE SUMPORT PROJECT
}

\author{
MARIOS MILTIADOU, CHRISTOS TAXILTARIS, GEORGIOS MINTSIS, SOCRATES BASBAS, \\ ANTONIA TSOUKALA, ANASTASIOS FYLAKTAKIS \& EVANGELIA PANOUSI \\ Laboratory of Transportation Planning, Transportation Engineering \& Highway Engineering, School of Rural and \\ Surveying Engineering, Aristotle University of Thessaloniki (AUTH), Greece
}

\begin{abstract}
The purpose of this paper is to present the outcomes and the experience gained through the elaboration of a transnational cooperation project SUMPORT (Sustainable Urban Mobility Plans - SUMPs - in MED-port cities, which comprised elaboration of sustainable mobility plans and pilot or permanent implementation of mobility measures in six (6) Mediterranean cities with ports. Based on a joint methodology for implementation, monitoring, and evaluation, and adjusted to the type of action (planning, implementation), three sustainable mobility plans (SMPs) have been developed (one as urban plan, the second as regional - integrated with the city's SUMP - and the third as a micro-SMP within a port - integrated with the city's SUMP as well). In addition, different types of measures, which had been planned in pre-existing SUMPs have been implemented, targeted to the improvement of active mobility (bike lanes, bike-sharing systems), enhancement of intelligent transportation systems for public transport and parking management, testing of car-pooling potential for workers at ports, and simulation of a new maritime public transport service for decongestion of coastal roads traffic. This paper presents the results of the planning exercises and implemented measures and highlights the lessons learnt from their deployment in different environments/contexts, which have been used for transferring this experience to other Mediterranean cities.
\end{abstract}

Keywords: SUMPORT, sustainable mobility plans, mobility management measures, case studies.

\section{INTRODUCTION}

European transnational cooperation programs, as other means of project European Union (EU) co-funding, provide the opportunity to public entities and academic, research and other bodies to implement projects of mutual and international interest. Beside pure research and technological development activities, territorial programs offer possibilities for networking of cities in tackling specific issues, among others mobility and transport.

In the framework of such a territorial cooperation program (EU Interreg Mediterranean Program) through co-funding by the European Regional Development Fund (ERDF) and the Instrument for Pre-Accession (IPA) II, SUMPORT was implemented in the period 20172019. Under the thematic area "Urban Transports", the project aimed to contribute to outspread sustainable mobility planning across the Mediterranean area in the countries along its northern coastline, namely in Durres (Albania), Koper (Slovenia), Kotor (Montenegro), Limassol (Cyprus), Regional Unit of Thesprotia (RUTH) - Igoumenitsa (Greece) and Valencia (Spain), through improved planning and testing of specific measures.

These cities face similar problems, such as congestion, pollution, and noise. Moreover, they have similar issues to confront, namely the geographical limitations of the coastal boundary and the existence of the ports and the burden of the traffic owed to passenger and freight flows through their ports. In terms of mobility planning, some cities are well advanced, having the economic potential and proactiveness to promote sustainable mobility, but on the contrary others are substantially lagging. 


\section{SUSTAINABLE MOBILITY PLANNING FRAMEWORK: SUMPORT CONCEPT AND METHODOLOGY}

\subsection{Overview of sustainable mobility planning framework: The SUMPs context}

The rational organization of mobility in the urban environment in the light of the sustainable mobility principles, constitutes an important solution to the problems of modern cities, e.g., air and noise pollution, traffic congestion and accidents, impact on public health, occupation of vulnerable road users' vital space and reduced social cohesion. In this framework, the European Commission (EC) urges the cities to elaborate SUMPs through a series of policy, communication - to the EU institutions - and other working documents, such as the Thematic Strategy on the urban environment [1], the Green Paper [2] and Action Plan [3] for urban mobility, the 2011 White Paper towards a competitive and resource efficient transport system [4] and particularly the Communication "Together towards competitive and resource efficient urban mobility" [5] setting out the SUMP concept in its Annex 1.

In addition, the EC exploiting the know-how and best practices of its members - with protruding examples being the French Plan de Déplacements Urbains (PDU), the English Local Transport Plans (LTP) and the Italian Piano Urbano della Mobilità (PUM) [6] - and experts' opinions, in 2013 issued the first guidelines for SUMPs elaboration [7]. Not many years after, following extensive evaluation and consultations with experts and practitioners, these guidelines have been revised [8], bringing SUMPs forward as a more powerful regulatory tool through enhancement of the guidelines regarding planning, financing and implementation of measures. At the same time, the improvement and somewhat simplification of the SUMP process, contributed to making the guidelines more flexible and easier to use methodological tools.

SUMP is a strategic plan designed to satisfy the mobility needs of people and businesses in cities and their surroundings for a better quality of life. It builds on existing planning practices and takes due consideration of integration, participation, and evaluation principles [5]. Actually, SUMP has a spherical and anthropocentric logic, focusing especially on citizens that belong in vulnerable categories, their mobility and their characteristics [9], [10]. The development of an integrated transport and mobility system that SUMP represents, requires a more advanced approach in terms of interdisciplinarity, co-modality, interMunicipality, timelessness, and (mainly) in terms of a better structured participatory process comprising consultations with involved stakeholders and the civil society. Also, strong components of the SUMPs are the structure of the transport and mobility system with organization of the public space and the coordinated and mutually reinforcing action of involved bodies of different institutional boundaries, aspects that are referred to in EC documents [5]. Finally, concerning the effectiveness and efficiency of a SUMP, these are maximized by mandatory methods for its monitoring and evaluation (ex-ante and ex-post).

The measures that are used in SUMPs are derived mainly from the traditional arsenal of sustainable mobility that contains promotion of public transport and active modes, and simultaneous prevention of private cars use (push-pull measures), as well as practices of mobility services that encourage the change of mentality of people towards sustainable forms of mobility (car-pooling, car-sharing, bike-sharing, enterprises mobility plans, transport on demand, etc.). Of course, there are other measures based on Information and Communication Technologies (ICT) and smart mobility aspects, following the continuously evolving requirements of the EU for, inter alia, investing in environmentally friendly technologies, digitalization, decarbonization of energy and transport sector, and electro-mobility [11]-[13]. 
The concept of SUMP and related European guidelines, which are core elements of the 2013 Urban Mobility Package, have been widely used and proved effective and useful for local authorities, planners and stakeholders [14]. More and more countries are mobilizing in SUMPs elaboration or are eager to be involved in such process and in fact, countries that did not traditional have the philosophy of sustainable mobility; like Greece, where very recently the elaboration of SUMP become obligatory by Law, for cities with population of 30,000 inhabitants or more. As EU member states are constantly heading towards sustainable mobility planning, non-EU countries in South East Europe (SEE) are lagging, but SUMPs elaboration is becoming not so rare anymore. SUMPs are financed by any possible means (international financial institutions, donors, other funding programs) and their development is one of the main objectives of the Sustainable Urban Mobility in South East European Countries (SUMSEEC) Roadmap [15], which motivates these countries towards this direction.

\subsection{SUMPORT methodology}

\subsubsection{SUMPORT conceptual design}

In 2015, namely two years after the release of the EU urban mobility package and issuance of the first SUMP guidelines, the project idea was conceived, acknowledging that SUMPs had not been widely spread in the Mediterranean (MED) area and in SEE and that are not entirely - but partially - applied, resulting in solely actions aligned with SUMPs' concept but with doubtful positive impacts and not in an integrated manner.

What was common among the participating cities of the project is their ports. They are coastal cities with this major pole of attraction and generation of traffic, with apparently a dominant role in everyday life, culture, land uses, employment and habits, including habits for mobility. Actually, the existence of the port, and the location in the Mediterranean are the only connecting factors among these cities. Each of them has a unique character, different size and population and different level of economy and development. Others are major cities with substantial volume of traffic, others are much smaller but still volumes of passengers or cargo and seasonality of high touristic flows are aggravating the conditions in each of them.

Additionally, these cities have different experiences and capacities in mobility planning; different readiness and level of planning. There were partners that at that time had already SUMPs in place, others with SUMPs under elaboration and others with no SUMPs at all, not even in other cities of the same country. Therefore, the aim was to act on different levels, according to the particularities of each city, region or country.

The project's design, at conceptual level, comprised interactions among the partners for identification of the plans and measures subject to each partner's standing point related to urban mobility planning. Always aligned with the call's requirements, the project included two major groups of activities: "Testing" and "Transferring." The first would be the core cluster of mobility planning exercises, measures implementation and testing and parallel training of staff and practitioners, while the second would be to transfer best practices and lessons learnt to target groups in the countries represented in the project [16].

\subsubsection{SUMPORT methodological approach}

The core cluster constituted the pure technical component that included eleven (11) actions to be undertaken at local level by the relevant partners: plans and studies $(\mathrm{P} / \mathrm{S})$ and smallscale investments (SSI) implementing mobility measures in various domains of intervention, such as promotion of active mobility, increase of use of Information and Communication Technologies for enhancement of public transport and for better traffic and parking 
management, and car-pooling. These actions are summarized in Table 1 (cities/regions in alphabetical order) per category and character (permanent or temporary):

Table 1: Case studies and type (plan/study or small-scale investment, permanent or not). (Source: Own elaboration, based on [17].)

\begin{tabular}{|c|c|c|c|}
\hline $\begin{array}{l}\text { City/Region/ } \\
\text { Port }\end{array}$ & Case study & $\begin{array}{l}\text { Type }(\mathrm{P} / \mathrm{S} \\
\text { or SSI) }\end{array}$ & $\begin{array}{c}\text { Permanent/ } \\
\text { Temporary (for SSI) }\end{array}$ \\
\hline \multirow{2}{*}{ Durres } & SUMP elaboration & $\mathrm{P} / \mathrm{S}$ & Not applicable \\
\hline & Extension of existing bicycle lanes & SSI & Permanent \\
\hline Koper & $\begin{array}{l}\text { Implementation of measures for promoting } \\
\text { info-mobility (real-time information and } \\
\text { journey planning), park and ride and public } \\
\text { transport usage }\end{array}$ & SSI & Permanent \\
\hline Kotor & $\begin{array}{l}\text { Bicycle lanes implementation along the } \\
\text { coastal road }\end{array}$ & SSI & Permanent \\
\hline \multirow{2}{*}{ Limassol } & $\begin{array}{l}\text { Connection of the existing coastal bicycle } \\
\text { lanes }\end{array}$ & SSI & Permanent \\
\hline & Simulation of new maritime transport service & $\mathrm{P} / \mathrm{S}$ & Not applicable \\
\hline \multirow[t]{2}{*}{ RUTH } & $\begin{array}{l}\text { Extension of sustainable mobility principles } \\
\text { to the entire regional unit, harmonized with } \\
\text { Igoumenitsa SUMP }\end{array}$ & $\mathrm{P} / \mathrm{S}$ & Not applicable \\
\hline & $\begin{array}{l}\text { Extension of existing bike-sharing system in } \\
\text { Igoumenitsa }\end{array}$ & SSI & Permanent \\
\hline \multirow{3}{*}{ Valencia Port } & $\begin{array}{l}\text { Update of sustainable mobility plan of the } \\
\text { port }\end{array}$ & $\mathrm{P} / \mathrm{S}$ & Not applicable \\
\hline & E-bike-sharing system development & SSI & Temporary \\
\hline & $\begin{array}{l}\text { Upgrade of the car-pooling system for the } \\
\text { staff of the port }\end{array}$ & SSI & Permanent \\
\hline
\end{tabular}

These actions can be clustered, besides their general categorization in $\mathrm{P} / \mathrm{S}$ and SSI, according to their scope/field of intervention:

- $\quad$ Promotion of SUMPs for improving citizens quality of life.

- Reduction of motorized traffic, in line with pre-existing SUMP or Transport Master Plan or SUMP under elaboration.

- $\quad$ Promotion of shared mobility (alternative means of transport, shared modes, cycling and walking, public transport), again in line with pre-existing planning documents.

An overall implementation methodology was identified [18], describing the milestones, allocating roles and responsibilities and most importantly the guidelines to prepare the foreseen - so-called - "preparatory" studies per testing activity per partner [19]. The discrete methodologies for each testing activity were defined according to their subject and nature and it has not always been the case that the port-city interaction is affected.

Apparently, planning and implementation was directed to different levels: (a) at strategic level, like the SMPs elaboration (Valencia, Durres) and measures like the maritime transport service (Limassol), where obviously the ports have a role to play; (b) measures (such as carpooling, e-bikes) to be implemented by the port itself (Valencia) and the contact had to be the other way around, i.e., the port to involve the city in order to harmonize its SMP and measures with the wider city's SUMP; (c) a regional SMP (the one of RUTH), where the 
planning had to take into consideration the SUMP of the capital city that was being elaborated at the same time, and so the port had no role in this; and (d) measures that the port involvement was not needed at all, such as the cases of bike lanes implementation (Kotor, Durres, Limassol), bike-sharing (Igoumenitsa) and info-mobility (Koper), unless the planning foresaw an intervention in the vicinity of a port (e.g., placement of a parking for bikes or alignment of a bike lane by the entrance).

Immediately after, the partners presented their preparatory studies [20], where they indicated their approach tailored to the specificities of their activities, including a mapping of stakeholders their involvement plan and a Strengths-Weaknesses-Opportunities-Threats (SWOT) analysis. Upon discussion and acceptance of these studies, the partners proceeded to implementation.

Moreover, an evaluation methodology was defined, which would be the approach to assess the impact before and after the implementation of the pilot activities or present the exante evaluation of SUMPs and simulation activities. Key-Performance Indicators identified were clustered according to the nature of each testing activity and their anticipated impact [21].

In parallel, given that the target was not only to develop or implement the predefined mobility plans and measures, a training plan for municipal staff and practitioners/planners was developed for implementation, as well as a methodology for transferring [22] and structured plan for results portability [23] for transferring the experience and lessons learnt to local and national stakeholders (ministries, other municipalities in the same countries, mobility and spatial planners and practitioners) at specific transferring events [24] and by making widely available training material and outputs and results through a dedicated elearning platform [25].

\section{IMPLEMENTATION, LESSONS LEARNT AND PERSPECTIVES}

\subsection{Durres: SUMP elaboration and extension of bike lanes network}

\subsubsection{SUMP elaboration}

Municipality of Durres with 309,000 inhabitants, covers an area of $430 \mathrm{~km}^{2}$ and its urban area is $46 \mathrm{~km}^{2}$. The Municipality anticipated to develop its first SUMP, aiming to tackle the problems caused by the increased, especially seasonal (est. of 400,000 tourists per annum), traffic and to harmonize urban development with the transport modes according to people needs through efficient planning, management, and enhanced coordination of existing and planned investments in the periods 2019-2024 and 2025-2030.

For the needs of the SUMP, traffic and households' surveys were organized and analysis of the existing situation was carried out as the first step. Following consultations with stakeholders and scenarios assessment, the SUMP and its Action Plan for the functional area of the city were defined. The main stakeholders engaged were the national Institute of Transport, the Durres University, the Bike Association, Police, Public Transport Association, Durres Port Authority, Railway Directorate and residents.

In Durres, $26 \%$ of the daily trips are performed on foot or by bicycle. In 2011, in the urban areas of the city, the car share in the total trips to/from work was only $25 \%$, compared to $47 \%$ on foot and 3\% by bicycle. Despite high car addiction that followed the liberalization of car ownership after 1990, these notable percentages are explained by a combination of factors, economic and societal, besides the existence of some completely pedestrianized areas, bicycle lanes network and at the same time deficiencies of public transport services that are limited to lines along main road axes and connecting main settlements and other cities. Public 
transport, which is not supported by the state through any subsidies, is the last mobility option of the citizens that do not own or cannot use cars or move actively (walking or biking). Beside other measures, such as full pedestrianization of the city center, restriction of traffic in the surrounding of the pedestrian zone, $30 \mathrm{~km} / \mathrm{h}$ zones introduction, enhanced traffic and parking system regulation and management, improvement of public transport, etc., two terminals are proposed for promoting co-modality (sea, rail, bus, bike) in the city.

\subsubsection{Bike lanes network extension}

Durres is developed on a flat area and the climate conditions favor the creation and use of bike lanes. Pre-existing bike lanes extended to $6.5 \mathrm{~km}$ in total, consisted of two long stretches parallel to the coastline $(4.5 \mathrm{~km}$ along the touristic area and $2 \mathrm{~km}$ on the road parallel to the port). Several possibilities were examined in consultation with stakeholders, with different pros and cons, among the latter being the relocation of parking slots and the unavoidable need for facilitation of vehicles traffic in the vicinity to the port, especially near the gates.

Eventually, there were two potential extensions that could be implemented: the missing link between the existing bike lanes and an extension at the north-western end of the stretch nearby the Port, at its second entrance. However, due to other ongoing construction of road and pedestrian overpass in the area of the second segment near the port main gate (castle area) which didn't foresee space for a bike lane, it was decided to proceed only with implementation of the segment that would connect the existing bike lanes in an area where the bike lane is interrupted under the bridge of the main road network with high traffic from/to the port.

Several alignment alternatives were examined and, after having considered expropriation requirements, geometry, lighting system and sight conditions and safety, the best ones were defined in consultation with the main stakeholders, including the port. In absence of national design standards, the Italian standards were used. The new length of $240 \mathrm{~m}$ of bike lane costed approx. $€ 25,000$ and it now ensures continuity of exclusive infrastructure for citizens and visitors for performing shorter or longer, ordinary or recreational, trips by bicycle, not jeopardizing safety and in a more environmentally friendly way.

\subsection{Koper: Info-mobility and promotion of public transport}

The Municipality of Koper covers an area of over $300 \mathrm{~km}^{2}$, has more than 50,000 inhabitants, and there is located one of the biggest ports of North Adriatic. The city adopted its integrated transport strategy in 2017. Mobility in Koper is characterized by high share of use of private cars and the city targets to encourage co-modality and to increase the use of the public bus in the long term. The public transport is well-organized in the city, managed and financed directly by the Municipality. Its basic problem is the missing connection between the city and its suburban areas, from which daily commuting flows for work and education are originated. Koper has developed the basic transport open data platform needed to support the development of an information system, which enhances traffic management and analysis capabilities and provides information about parking places, suburban bus stops, intermodal travel planning, including combination of bus-cycling routes.

Specifically in the framework of SUMPORT, Koper implemented the upgrade of a regional mobility center, installation of necessary equipment (buses with GPS sensors, monitors at bus stops with real-time information) facilitating use of public transport, creation of smart parking system (sensors at parking for information on availability of slots near suburban bus stops) encouraging "Park \& Ride" and development of smartphone applications for provision of real-time information with integrated journey planning possibilities. 
The ability to integrate all traffic data in the traffic information centre and to distribute the information to the citizens and users aims to make better use of public transport and change mobility habits. The mobility App developed provides real-time overview of the situation on road network, enabling better traffic management and cooperation with the national information centre, reducing traffic and $\mathrm{CO}_{2}$ emissions by increasing the use of public transport. The implementation of this action demonstrated the broad experience of the Municipality in implementing measures for sustainable mobility, a well-established participatory process in harmonization with the city SUMP that was adopted in the meantime against the generalized culture that considers the private car as a "status symbol" resulting in small public transport share over the years. Through a total budget of $€ 150,000$, the sustainable and integrated transport strategy has been reinforced and increase of public transport use through Park and Ride and co-modality (bus-bike) has been promoted by facilitation of daily trips planning in a more environmentally friendly and efficient way.

\subsection{Kotor: Coastal bike lane implementation}

Kotor is a small Municipality which attracts substantial volume of touristic and visitors flows, as well as large amount of transit traffic. The continuous increase of tourism creates seasonal problems, which are further aggravated by the fact the entire traffic, both transit and local, moves along the main highway that crosses the city. In addition, arrival of cruise ships and of more than half a million visitors leads to frequent halts in traffic on the highway, causing traffic congestion in the entire central zone of the city. Due to the frequent traffic flows disruptions, two-wheeled traffic has increased despite the absence of special infrastructure.

Kotor has a Local SMP developed under the IPA Adriatic Program 2007-2013. Within SUMPORT, the implementation of a bike lane along the $5 \mathrm{~km}$ long coastal road aimed to offer the possibility to citizens and visitors to perform ordinary or recreational trips by bike in safety, contributing to change of mobility habits and reduction of private cars use. Given the spatial limitations (implementation along a bidirectional narrow street with scarce intermediate vertical connections to the parallel highway for accessibility to the coastal road and properties) change of regime to one-way road had to be considered and was decided for the middle stretch of $1.8 \mathrm{~km}$. Limitations in public space required abolishment of 120 seasonal car parking spaces on the first stretch $(2.7 \mathrm{~km})$ and other bike/pedestrian lanes on both stretches that maintain bidirectional road traffic. Coordination with authorities and citizens was vital to obtain an optimal technical solution, which eventually comprised horizontal and vertical signage and equipment installation in all segments where exclusive bike lane is provided (including stretches with contra-flow movement) or is shared with pedestrians. This provides a useful experience for creating specific know-how for mobility measures planning in case of natural and other physical/structural constraints.

\subsection{Limassol: Extension of coastal bike lanes and simulation of new maritime service}

Limassol is the second largest city in Cyprus, and the main port of the island is located there. Elaboration of SUMPs in Cyprus is responsibility of the Ministry of Transport, Communications and Works, and while SUMPORT was being implemented the SUMP of Limassol metropolitan area was under elaboration. The metropolitan area of Limassol has more than 200,000 inhabitants, half of them living within the Municipality. This SUMP was completed in 2019 and contains policies and measures for implementation by 2030. The current modal split shows that the role of car is dominant $(92 \%)$ in contrast with public transport (1.5\%) and walking and cycling $(6.5 \%)$. Change of modal split towards sustainable 
mobility patterns is a main target for the Municipality and the SUMP, through improvement of public transport services and integrated bike lanes network, as well as an efficient and harmonized connection of the port with the city.

With a total budget of $€ 165,000$, the Municipality planned the simulation of introducing a maritime public transport system in Limassol and the design and implementation of a permanent bike lane to link the existing bicycle lanes on both sides of the New Limassol Port. Through the latter, the existing gap of about $4 \mathrm{~km}$ in bicycle infrastructure of the city's New Port with the town's most important points of interest and areas of trips production/attraction would have been partly bridged, by constructing $1 \mathrm{~km}$ of bike lane at its western end, near the New Port. This way, uninterrupted and exclusive bike lane infrastructure would be ensured for citizens and visitors for their ordinary or recreational trips by bike, in safety and in an environmentally friendly way, thus contributing to mobility habits change.

In parallel, the Ministry of Transport, Communications and Works scheduled the reconstruction of the road at a length of $2.5 \mathrm{~km}$. The Municipality had to adjust to this project and therefore, provision for a bike lane was included at its entire length and supplemented it with design for the rest of the gapping length up to the city center, where no road infrastructure is in place. Despite that preparatory works for implementation started at a section out of the Ministry's project as temporary solution until the missing road link would be constructed, works were stopped due to other ongoing construction projects in the area and the reduced standards used for fitting the bike lane in the available road infrastructure.

Therefore, what has been achieved within SUMPORT was not an implementation by the Municipality, but only a design for its entire missing length along the coast. Implementation has been completed for $2.5 \mathrm{~km}$ by the Ministry and implementation of the rest of the bike lane has been included in the adopted SUMP. Since the project is considered a high priority for the city and port for attracting large cruise ships to the port, anticipation is that it will be implemented much sooner than 2030 that is the horizon date of the SUMP action plan.

Concerning the simulation (feasibility study) of maritime public transport system, it aimed to explore the potential of provision of an alternative solution to serve the connection between the Limassol New Port with various parts of the urban complex along the coastal front in a length of approx. $25 \mathrm{~km}$. The study examined whether such a service would be financially and economically viable and under which characteristics it could attract interest from the private sector for its implementation. It was found that with an investment of $€ 2$ million (equally for infrastructure and equipment, i.e., construction/reconstruction of piers, electronic payment systems, and procurement of two vessels - bus taxis), the new service could attract 195,000 passengers at its first year of operation (2022), with a perspective to reach 278,000 passengers in 2045. These figures correspond to trips that would be otherwise performed by car or taxi along the coastal road network, and therefore the introduction of such a service would mean a serious relief on the already aggravated road network and result in respective environmental benefits from trips of tourists disembarking at the port and visiting the city. Generated revenues from ticketing will start from $€ 1.36$ million after the first year of operation and reach $€ 1.95$ million at the end of the analysis period (2045).

3.5 Thesprotia: Extension of the principles of sustainable mobility planning in RUTH and upgrade of the bike-sharing system in the city of Igoumenitsa

RUTH extends in an area of $1.515 \mathrm{~km}^{2}$ and has a population of around 43,500 residents. It consists of three municipalities, with Igoumenitsa as capital, where the port is located as node of the Trans-European core ports network. It is mostly mountainous and among the least populated regional units in Greece in terms of population density. Due these particularities 
the region faces connectivity, accessibility and infrastructural problems, as well as significant problems with urban public transport, and consequently high car usage and dependence due to absence of railway connection, limited bike infrastructure, lack of cooperation with tour operators, and generally lack of experience in mobility planning.

\subsubsection{SMP geographical coverage extension}

It had been initially planned within SUMPORT to prepare a SUMP for the city of Igoumenitsa. However, up to approval of the project, the city of Igoumenitsa had assigned the elaboration of the city SUMP to external consultant. Thus, a change of scope was inevitable. RUTH undertook the preparation of an integrated plan for the extension of the SUMP principles in its territory, in line with the one of Igoumenitsa, aiming to integrate the planning at regional level and promote the adoption of sustainable mobility habits, turning to mass transportation systems for long-distance (interurban) trips.

Considering the particularities of the region (low level of connectivity, large scattering of settlements, low population density and existing weaknesses of public transport system), the focus was placed on public transport as the only way that could change the modal split towards more sustainable mobility. Ensuring harmonization with Igoumenitsa's SUMP had been in the core of the applied methodology, which comprised public consultations, data collection, analysis of the characteristics of the existing transport system, development of a commonly shared vision for promoting sustainable mobility with the involvement of stakeholders, definition and assessment of scenarios, meetings with stakeholders for the finetuning of policies and measures and the adoption of the SMP and its Action Plan. The engaged stakeholders included the local authorities (Municipalities), the Port of Igoumenitsa, the Chamber of Commerce, the Public Transport Administration, Bike Associations, Police, etc. Consolidation of the participatory sustainable mobility planning has been a main benefit of this exercise, apart from the enlargement of the studied geographical area, from the Municipality to the regional unit.

\subsubsection{Extension of bike-sharing system in Igoumenitsa}

This permanent measure concerned the extension of the bike-sharing system in the city of Igoumenitsa that had been implemented in 2017 in the framework of IPA Adriatic Program 2007-2013. The extension comprised procurement of additional bikes and the installation of a third rental station, extending the length of potential rental from $1.5 \mathrm{~km}$ to $2.6 \mathrm{~km}$, covering almost entirely the coastal front of the city, from the port to the University area. This has achieved to increase the previously insignificant bicycle use, also due to the poor bicycle infrastructure. With some improvements of this infrastructure in the meantime, the demand and utilization rate of the bike-sharing system has increased, particularly since the COVID19 pandemic and the turn of people to active mobility.

\subsection{Valencia Port: SMP update, e-bike-sharing and car-pooling systems}

Valencia is third largest city in Spain with around 800,000 inhabitants and extends in an area of $138 \mathrm{~km}^{2}$, out of which less than half $\left(62.5 \mathrm{~km}^{2}\right)$ correspond to the city. The port of Valencia is the first container port in the Mediterranean, but also an important cruise ship port, serving one million passengers annually, out of which $40 \%$ cruise passengers. With this large volume and wide range of activities, the port concentrates more than 6,500 workers and its functions generates and attracts traffic volumes for freight, tourism and commuting/business. The Port of Valencia participated in SUMPORT through the Valenciaport Foundation (VPF) for Research, Promotion and Commercial Studies of the Valencian region. 


\subsubsection{SMP update}

With a budget of $€ 40,000$, it was anticipated to renew the port's SMP for 2012-2017 and harmonize it with the city SUMP for ensuring an improved city-port interaction. The methodology comprised analysis of the existing SMP, data collection and analysis, elaboration of the SMP with strategic objectives and an action plan to meet these objectives, analysis of the needs of the port community and fine-tuning with stakeholders, and communication and dissemination among the Port Cluster.

\subsubsection{E-bike-sharing system in Valencia Port}

As cruise traffic has been continuously growing, the port is working on the development and implementation of more sustainable ways of mobility for cruise passengers. In this aspect, the introduction of an e-bike-sharing system in the port has been tested for a period of six (6) months. One parking/charging station and ten (10) e-bikes were provided, at the cost of $€ 5,700$. This service was integrated with the city's parking/charging stations and was targeted to cruise passengers, aiming to contribute to avoidance of car trips and emissions. This measure faced problems in its testing, due to complexity of the process for authorizations and lack of interest from e-bikes service providers. As commented in the following section, the main obstacles identified for its future success are the price and the preference of the passengers to hire services that are already available on the cruise ship.

\subsubsection{Upgrade of car-pooling application for staff of the Valencia Port}

The existing car-pooling system addressed to the large volume of port workers had to be assessed, updated and improved in order to promote the rational use of private cars by the port workers and result in multiple benefits, such as noise and emissions reduction along the road network and the port, fuels savings and savings in public space within the port area. A smartphone application had been developed according to the previous SMP of the port, but several shortfalls in functionalities and usability were identified.

With a budget of $€ 5,700$ and through review of the current tool, test and analysis of the existing systems, the test users identified the problems and defined potential functionalities and improvements. Based on these improvements and gap analysis, the new requirements were defined, also through assessing other similar mobility apps in place in Spain and abroad. Then, the new technical specifications were defined, testing of the new application was performed by fifty (50) employees of the Port for a period of one year, and the impact was evaluated based on methodology provided by the Spanish Ministry of Ecological Transition.

\section{OVERALL EVALUATION AND PERSPECTIVES}

Ex-ante and ex-post evaluation of the elaborated planning tools and implemented measures, respectively, is very useful for the assessment [26] and transferring of the gained experience, through identified shortfalls and problems faced at all stages of the elaboration/ implementation process.

\subsection{Mobility planning studies}

The mobility studies elaborated within the project vary from an entirely new city SUMP to an update of an enterprise mobility plan and to an extension of mobility planning principles to a regional context. Under these terms, comparisons cannot be sound due to the differences of geographical scale, thematic coverage and the particularities of each implementing entity.

In the first case (Durres), the planning concerns an attempt to elaborate a city's first SUMP, without previous similar experience, with limited capacities and available funds. At 
the time of SUMPORT conception this should have been the first SUMP in Albania based on the EU SUMP guidelines framework (note: in 2017 the city of Shkoder also developed a SUMP for the period up to 2023 and in 2020 the city of Tirana for the period up to 2030). Even under these circumstances the Municipality achieved to institutionalize its first SUMP, as the basis for future planning, financing and implementation of sustainable mobility measures. Thus, the level of satisfaction regarding the final output was average $(3 / 5)$, the level of awareness the same, while the level of satisfaction regarding the participatory process was high (4/5). Out of eight (8) key-actors and stakeholders identified and mapped, six (6) stakeholder groups were finally involved. The scenario adopted by the SUMP includes policies and measures regarding public transport, bike lanes network, Park and Ride and comodality promotion, and traffic management and accessibility improvements.

Durres is one of the major economic centers and transport hubs in Albania and, being close to the capital city of Tirana, is part of the "Durana" (DURres-tirANA) area development project. What has been recognized is that there is strong political will for improving urban mobility through appropriate planning and low-cost measures, as well as social demand for efficient mobility ensuring an environmentally friendly lifestyle. The dominance of cars over public space, budget limitations, low involvement of local stakeholders and mainly the lack of previous experiences for SUMP elaboration have been the major risks and obstacles that had to and must be overcome in planning and implementing mobility measures. Institutionalization of the first SUMP of Durres was the main achievement and the perspective is to capitalize the experience gained towards enhancement of sustainable mobility planning, also through an enhanced participatory framework and process.

In the second case (Valencia port), the planning concerns a Port with a pre-existing 5year mobility plan and substantial experience in the field, also originating from the SUMP of the city, which the new SMP should be harmonized with. This shapes a totally different reality and conditions for working with stakeholders based on an already well-known methodology, practices and lessons from the past. Hence, the level of satisfaction regarding the output was higher (3.7/5) and regarding the participatory process was high (4/5) too. Among the 636 invited individuals (employees and workers of the port), 47 were involved in the participatory process.

In the third case (RUTH), it had been originally planned to elaborate a SUMP for the main city of the region, but in the meantime the SUMP elaboration was assigned to an external consultant. This led to change of scope, to a meaningful planning exercise to expand the sustainable mobility principles to a geographical area beyond the main Municipality, covering a region that extends from the port and its few flat areas to a mountainous relief, with scattered and small (in area and population) settlements, interconnected only through the road network, the old national and peripheral network and a modern motorway of national importance as its backbone. Therefore, the focus was primarily on public transport improvement for the intra-regional mobility. According to the ex-ante evaluation, the level of satisfaction regarding the output and the participatory process was high, while the level of awareness was medium. This could be explained by the fact that among the twelve (12) identified and mapped key-actors and stakeholders only three stakeholder groups were finally involved in the participatory process.

Concerning the feasibility study for potential introduction of a maritime public transport system in Limassol, such a service could be viable and very beneficial for the transport system of the city, however with a series of risks identified: the existing high dependence on private car and lack of sustainable mobility culture, possible negative reactions from stakeholders (association of taxi drivers, tourist bus companies, environmental organizations etc.) and likely no interest from private investors. 


\subsection{Urban mobility measures}

The evaluation permanent measures implemented within the project demonstrates different levels of impact, acceptance and level of satisfaction, depending on their type and scale of intervention.

Regarding the cases that concerned bike lanes implementation (Limassol, Durres and Kotor), different problems were encountered that affected the initial planning and designs prepared: In Limassol, the designed bike lane was finally implemented by funds of the Ministry of Public Works and full implementation was extended beyond the project duration. In Durres, full implementation was prevented by ongoing construction works in part of the project area. Finally, in Kotor, the implementation delayed for several months due to Municipal elections and absence of competent Mayor to sign the procurement of works and decision/contract for implementation. These facts prevented the proper ex-post evaluation of the specific measures. Only in Durres it was possible to measure the daily use of the small section added to interconnect the existing bike lanes. With 100 cyclists per day counted on the specific section it was estimated that more than 1,500 monthly car trips were avoided.

Concerning the bike-sharing measures, one has been permanent (extension of the existing system in Igoumenitsa) and one temporary (testing of e-bike-sharing system in the port of Valencia). The overall levels of awareness and satisfaction were very good (4/5), while the utilization rates varied substantially: it was $54 \%$ for Igoumenitsa and only $10 \%$ for Valencia Port. This is explained partly by the pricing scheme, which has been the same as before for Igoumenitsa, while in Valencia Port, the vendor introduced very high prices (for up to $1 \mathrm{~h}$ $€ 9$, up to $2 \mathrm{~h} € 18$ and for entire day $€ 24.2$ ). Besides, cruise passengers are used to plan their trips to the city prior to their arrival at the port and were not aware for the e-bike renting potential. To this end, implementation of this specific measure will be reassessed in the future, combined with awareness raising and promotion activities to the target groups.

Regarding the car-pooling application for Valencia Port workers, in a testing period of 1 year, the levels of satisfaction and awareness for the updated application were considered very good (4/5), however it was only tested by 8 users with average trip length of $20.7 \mathrm{~km}$. The utilization rate was estimated to be below $2 \%$.

Finally, the implemented info-mobility measures and the deployed equipment in Koper as part of the city's SUMP had a wider scale of impact compared the other measures discussed in the above. This is due to the ability of the municipal authority to organize stepby-step implementation by combining available funding sources. Provided that the implementation period did not allow traffic counting throughout an entire year, it was estimated that the overall result of these measures will be that $1 / 3$ of the annual passengers $(3,000,000)$ will use public transport instead of private cars (assuming 2 persons occupancy on average), resulting in 2.25 million car-kilometers avoided on annual basis. Thus, level of satisfaction of the users has been quite high due to the increased and enhanced possibilities to use public transport. Yet, the persisting problem of high truck traffic has to be resolved with the Port and, for this purpose, the traffic centers will be interconnected for common use of data, processing and decision making.

\section{CONCLUSIONS AND DISCUSSION}

Mediterranean cities with ports have similar issues to confront regarding mobility aspects. They have their particularities and different needs than inland and polycentric or radial cities. Urban transport and mobility are directly affected by their ports' capacity, operations and type of provided services (passengers, freight, as well as cruise). 
Port and city relation is many times uneven, ports being business oriented and having a dominant role over the city, its planning and its people everyday life. Better planning, targeted solutions and measures promoting sustainable mobility can contribute to improvement of the functionality of the cities in a somehow better harmony with their ports. SUMPORT aimed to provide support to the participating cities with appropriate tools and guidance (a) to develop their SMPs in synergy between city and ports, the latter being major trip generators/attractors that affect mobility and accessibility, and (b) to implement measures identified by SMPs to support multimodal and environmentally friendly logistics and public transport services all-year round, also taking into account the seasonal increase of cities' population with tourists, long-stay visitors, transit visitors and cruise passengers.

The case studies presented in the paper vary in scale, significance, and nature, since others concern mobility measures implemented within the project timeframe (bike lanes, bikesharing service, info-mobility service, car-pooling application) and others planning documents that have been adopted and shall be funded for implementation (SMP, simulation of maritime public transport). Differences among the cities' planning capacities were confirmed and, in addition, differences regarding stakeholders needs and level of involvement have been also identified, particularly regarding ports. The presented case studies included implementation by a port (Valencia Port) with more or less direct or entire jurisdiction for decision making and implementation, implementation of measures adjacent to the port or planning of services or infrastructure that interacts with the port, as well as other measures or planning with no relevance to the port.

SUMP principles are increasingly promoted during the last decades and more intensively in the last years, especially with the boost given by the EU through its related policies and guidelines. These are applied at different speeds by various cities all over Europe, sometimes successfully and sometimes not. SUMPORT contributed to the take-up of SUMPs by development of such plans and relevant measures implementation in different contexts (in cities/countries with no experience in the field) and by transferring experiences and lessons learnt to other MED cities with similar characteristics (e.g., demographic and socioeconomic) and mobility patterns. To this end, beyond the implementation of the foreseen e-learning platform for sharing the project's results, the platform was enriched with case studies from other studies or pilot actions implemented by other projects of the MED Program, representing an integrated info-point for planners and practitioners in the region and beyond.

The common target of increasing the level of SUMPs geographical spreading was served through all projects implemented in parallel with SUMPORT under the same thematic area (low-carbon urban transport systems). For example, MOBILITAS has worked on mobility for nearly-zero $\mathrm{CO}_{2}$ emissions in Mediterranean tourism destinations. Soft and electric mobility, shared and public transport, ITS, cooperation and coordination with increased participation and enhanced transparency and governance, are among MOBILITAS recommendations for sustainable mobility for its specific pilot areas [27], which are identical or aligned with the results and recommendations emerging from SUMPORT case studies.

Collective efforts of these territorial cooperation projects in the Mediterranean under the umbrella of the Urban Transports Community of the MED program, resulted in a handbook on sustainable mobility in the MED area, developed by the same project [28] and the elearning platform and materials are available on EU Urban Mobility Observatory (ELTIS).

Working towards sustainable and low-carbon mobility in the Mediterranean remains a goal for the years to come, serving the EU Green Deal objectives for better use of the different modes of transport, smart, digitalized, and automated mobility and management systems, use of alternative fuels and electro-mobility for pollution reduction. As the MED Program works in line with the EU Regional Development and Cohesion Policy, it is anticipated that the new 
programing period 2021-2027 related to transport and mobility will be directed to the same orientation, in a holistic approach towards smarter-innovative, greener and low-carbon, and better-connected Europe through mobility and ICT connectivity. Solutions that have been tested in the framework of projects such as SUMPORT can be effective after their scale-up or implementation, as long as they contribute to already approved SUMPs and their action plans, thus effectively taking advantage of all funding opportunities available to cities and regions.

\section{ACKNOWLEDGEMENTS}

The authors wish to acknowledge the contribution of all the SUMPORT project partners (Central European Initiative, International Organization based in Italy as Lead Partner, Foundation of the Valentian Community to promote strategic urban development and innovation - Las Naves, Spain, Institute for Transport and Logistics Foundation - ITL, Italy, Durres Municipality - Albania, City of Koper - Slovenia, Kotor Municipality - Montenegro, City of Limassol - Cyprus, Thesprotia Regional Unit - Greece, and Valencia Port - Spain) and the associated partners (Port Authority of Valencia, Cyprus Port Authority, Port of Koper, Port of Kotor and Port of Igoumenitsa) for the cooperation in the framework of this project that brings important results for outspreading further the implementation of policies and measures that serve the sustainable mobility principles.

\section{REFERENCES}

[1] European Commission, COM (718) Thematic strategy on the urban environment, 2006.

[2] European Commission, COM (551) GREEN PAPER towards a new culture for urban mobility, 2007.

[3] European Commission, COM (490) Action plan on urban mobility, 2009.

[4] European Commission, COM (144) WHITE PAPER Roadmap to a single European transport area - Towards a competitive and resource efficient transport system, 2011.

[5] European Commission, COM (913) Together towards competitive and resourceefficient urban mobility, 2013.

[6] Offner, J.-M., Les Plans de Déplacements Urbains, La Documentation Française: Paris, 2006.

[7] Rupprecht Consult, ELTISplus Guidelines - Developing and Implementing a Sustainable Urban Mobility Plan, 2013.

[8] Rupprecht Consult (ed), Guidelines for Developing and Implementing a Sustainable Urban Mobility Plan, 2nd edn, 2019.

[9] Tsoukala A., Organization of multimodal systems of urban trips, with emphasis on quality parameters of the urban environment. $\mathrm{PhD}$ thesis, Aristotle University of Thessaloniki, 2009.

[10] Taxiltaris, C., Tsoukala, A., Mintsis, G. \& Basbas, S., Vers un modèle de Plan de Déplacements Urbains pour les villes Grecques. 9e séminaire francophone est-ouest de socio-économie des transports à Lisbonne, au sein de la 12ème conférence mondiale sur la recherche dans les transports (WCTR), 11-15 Jul. 2010, Lisbon, Portugal, 2010.

[11] European Commission, COM (789) Sustainable and smart mobility strategy - Putting European transport on track for the future and Annex, 2020.

[12] European Commission, COM (640) The European green deal and Annex, 2020.

[13] POLIS, Rupprecht Consult - Forschung \& Beratung GmbH (eds), Topic Guide: Planning for More Resilient and Robust Urban Mobility, 2021. 
[14] European Commission, SWD (47) Evaluation of the 2013 urban mobility package, 2021.

[15] Kolega, B. \& Dubravka, B. (eds), Sustainable Urban Mobility in South East European Countries (SUMSEEC), Roadmap to Sustainable Urban Mobility in SEE Countries, 2018.

[16] Programme Interreg MED, SUMPORT Partners: Project application form - Version 3 - Approved. Project SUMPORT, RN 1441102176, 2017.

[17] Miltiadou, M., Mintsis, G., Basbas, S., Taxiltaris, C. \& Tsoukala, A., Sustainable urban mobility plans in Mediterranean Port-cities: The SUMPORT project, data analytics: Paving the way to sustainable urban mobility. Proceedings of 4th Conference on Sustainable Urban Mobility (CSUM2018), 24-25 May, Skiathos Island, Greece, eds E.G. Nathanail, I.D. Karakikes, CSUM 2018, AISC 879, pp. 410-417, 2019.

[18] Programme Interreg MED, Joint methodological framework for the implementation of WP3. Project SUMPORT, RN 1441102176, Aristotle University of Thessaloniki, 2017.

[19] Programme Interreg MED, Joint methodology for the preparation of elaboration/update of SUMPs and pilot actions implementation. Project SUMPORT, RN 1441102176, Aristotle University of Thessaloniki, 2017.

[20] Programme Interreg MED, Preliminary studies for the elaboration of SUMPs and launching pilot activities. Project SUMPORT, RN 1441102176, Aristotle University of Thessaloniki, 2018.

[21] Programme Interreg MED, Joint evaluation methodology. Project SUMPORT, RN 1441102176, Institute for Transport and Logistics Foundation, 2017.

[22] Programme Interreg MED, Joint methodology for transferring project results. Project SUMPORT, RN 1441102176, Las Naves, 2018.

[23] Programme Interreg MED, Plan of results portability. Project SUMPORT, RN 1441102176, Las Naves, 2018.

[24] Programme Interreg MED, Transferring events. Project SUMPORT, RN 1441102176, Las Naves, 2019.

[25] Programme Interreg MED, E-learning platform. Project SUMPORT, RN 1441102176, Central European Initiative, 2019. www.mobilitymed.eu.

[26] Programme Interreg MED, Final evaluation report. Project SUMPORT, RN 1441102176, Institute for Transport and Logistics Foundation, 2019.

[27] Programme Interreg MED, Strategies for sustainable and low-carbon mobility in Mediterranean tourist destinations. Project MOBILITAS, ENERGIES2050, 2019.

[28] Programme Interreg MED, A handbook on sustainable mobility in the MED area. Project MOBILITAS, Piano Strategico Rimini Venture, 2019. 